\title{
Hydrothermally Assisted Synthesis of Magnetic Iron Oxide-Chitosan Nanocomposites: Electrical and Biological Evaluation
}

\author{
Magda Dawy Badry ${ }^{1(D)}$, Mohammed Ahmed Wahba ${ }^{2, *}{ }^{(D)}$, Rabab Khaled Khaled ${ }^{1}$, , Mamdouh Moawad \\ Ali ${ }^{3}$ iD \\ 1 Department of Physical Chemistry, National Research Center, El-Behoos St., Dokki, Giza, Egypt \\ 2 Department of Inorganic Chemistry, National Research Center, El-Behoos St., Dokki, Giza, Egypt \\ 3 Department of Biochemistry, National Research Center, El-Behoos St., Dokki, Giza, Egypt \\ * Correspondence: mohamedwahba12@gmail.com;
}

Scopus Author ID 55618648700

Received: 21.03.2021; Revised: 20.05.2021; Accepted: 28.05.2021; Published: 18.06.2021

\begin{abstract}
Chitosan-coated- $\alpha-\mathrm{Fe}_{2} \mathrm{O}_{3}$ nanocomposites were successfully synthesized by a hydrothermal method via changing the ratio of chitosan (CS) to the iron ion precursor. TEM results showed good homogenous dispersion of $\alpha-\mathrm{Fe}_{2} \mathrm{O}_{3}$ nanoparticles inside the CS matrix with particle size in the range of 7-11 nm. XRD patterns proved the formation of a typical $\alpha-\mathrm{Fe}_{2} \mathrm{O}_{3}$ structure with traces of maghemite and magnetite that were proved by Raman spectra. The binding of CS to $\alpha-\mathrm{Fe}_{2} \mathrm{O}_{3}$ nanoparticles was likewise proved by Fourier transform infrared spectra. Magnetic measurements disclosed high saturated magnetization (Ms) values that declined (from 18 to $5.6 \mathrm{emu} / \mathrm{g}$ ) upon increasing the $\mathrm{CS} / \alpha-\mathrm{Fe}_{2} \mathrm{O}_{3}$ ratio. The frequency dependences of the dielectric constant and dielectric loss, at varying temperatures, recorded diminishing values with increasing frequency, in contrast, they showed a proportional relationship with temperature. The antiproliferative activities of the nanocomposites were assessed against four human cancer cell lines. The synthesized nanocomposites demonstrated higher cytotoxic activity against both liver cancer HepG2 and human colon cancer HCT116 cell lines, whereas they show no activity against breast MCF-7 and lung A549 cell lines. It was found that the anticancer activity of the nanocomposites correlates with their dielectric properties.
\end{abstract}

Keywords: $\alpha-\mathrm{Fe}_{2} \mathrm{O}_{3}$; Chitosan; Hydrothermal; Magnetic nanocomposite; Electrical; Antiproliferative activity.

(c) 2021 by the authors. This article is an open-access article distributed under the terms and conditions of the Creative Commons Attribution (CC BY) license (https://creativecommons.org/licenses/by/4.0/).

\section{Introduction}

Organic-inorganic hybrid materials have attracted increasing research attention for material scientists owing to their potential usage in technological and biological applications. The combination between organic and inorganic materials leads to advantages of flexibility related to various functional groups obtained from the organic moieties and mechanical and thermal stability acquired from incorporating the inorganic materials. Changing structures, compositions, and dimensions of these materials result in new and excellent properties suitable for various applications[1-5].

Among all types of iron oxides, hematite $\left(\alpha-\mathrm{Fe}_{2} \mathrm{O}_{3}\right)$ represents the most stable structure under normal conditions. It has been involved extensively in a broad range of applications such as photo-electrolysis, contrasting image reagents, drug delivery, pigments, transistors, gas sensors, solar cells, magnetic storages, optical devices, catalysis, biomedical materials, and 
electromagnetic devices [6,7]. Hematite has antiferromagnetism behavior at room temperature and has a complex defect structure having defect species such as oxygen vacancies and $\mathrm{Fe}^{2+}$ interstitials. It crystallizes in the rhombohedral crystal system with n-type semiconducting properties (optical band gap $\approx 2.1 \mathrm{eV}$ ). In the bulk form, hematite shows two types of magnetic transitions where the magnetic moments are antiferromagnetically organized below its Neel temperature (TN) (about $950 \mathrm{~K}$ ), while it undergoes a Morin transition (TM) where the magnetic moments are reorganized parallelly to the rhombohedral axis at about $260 \mathrm{~K}$. On the other hand, hematite nanoparticles demonstrate additional magnetic transition at about $140 \mathrm{~K}$ , referring to blocking (TB) temperatures, at which no hysteresis is detected $[8,9]$.

It is conventionally compromised that $\left(\alpha-\mathrm{Fe}_{2} \mathrm{O}_{3}\right)$ is non-magnetic and based on its low magnetization values (less than $1 \mathrm{emu} / \mathrm{g}$ ), it is not suitable for applications demanding external magnetic fields. However, many reports clarified that upon reducing the size to the nanoscale, materials reveal new and remarkedly different properties from their bulk counterpart $[10,11]$. For instance, Manukyan et al. reported synthesizing of $\alpha-\mathrm{Fe}_{2} \mathrm{O}_{3}$ nanorod and nanoparticles with high magnetization values (21-85 emu/ g) [12]. Novoselova reported a successful route for synthesizing exceptionally highly magnetized $\left(51 \mathrm{emu}^{-1}\right)$ hematite nanoparticles [13]. Several techniques have been used to synthesis nano-sized materials. Nowadays, the hydrothermal technique has found its place in numerous branches of science and technology because of reduced contamination, low synthesis temperature, and control of particle size by changing the hydrothermal temperature [14-16]. The aggregation of magnetic nanoparticles is also representing a major obstacle against their practical application usage. This could be assigned to the high surface area as well as the magnetic dipole interaction between these particles. Dispersion in a biopolymer matrix could provide a successful key to overcome this challenge[17-20].

CS is an abundant biopolymer formed by the deacetylation of chitin, a naturally happening polysaccharide found in shells of crustaceans. CS is a unique cationic, hydrophilic polymer possessing useful properties such as small toxicity, excellent biodegradability, biocompatibility, and high positive charges, which simply form polyelectrolyte complexes with negatively charged entities [21-23]. It has susceptivity likewise to chemical modifications owing to the existence of reactive hydroxyl and amino functional groups. Iron oxide nanoparticles incorporating into a chitosan network could improve the nanoparticles' magnetic, thermal properties and biocompatibility and extend its range of applications.

In this study, a simple hydrothermal method was used to synthesize $\alpha-\mathrm{Fe}_{2} \mathrm{O}_{3} /$ chitosan (HC) nanocomposites using different ratios of the biopolymer chitosan (CS) to $\alpha-\mathrm{Fe}_{2} \mathrm{O}_{3}$. The structural, morphological, magnetic, and electrical properties of the prepared nanocomposites were studied. The antiproliferative activities against breast MCF-7, liver HepG2, lung A549, and colon HCT116 human cancer cell lines were evaluated using doxorubicin as a standard drug. Finally, the anticancer activity of the nanocomposites was correlated with their dielectric properties.

\section{Materials and Methods}

\subsection{Synthesis of $\alpha-\mathrm{Fe}_{2} \mathrm{O}_{3} / \mathrm{CS}$ nanocomposites.}

$\alpha-\mathrm{Fe}_{2} \mathrm{O}_{3} / \mathrm{CS}$ nanocomposites were synthesized by mixing $\mathrm{FeCl}_{2} .4 \mathrm{H}_{2} \mathrm{O}$ and $\mathrm{FeCl}_{3} .6 \mathrm{H}_{2} \mathrm{O}$ (PANREAC QUIMICA SA) in 1: 2 molar ratio (for iron ions) under stirring from an hour, the resulting solution was dropped slowly into $\mathrm{NaOH} 30$ wt.\% solution (Sigma-Aldrich Chemical 
Co., USA). The use of this ferrous/ferric molar ratio is a conventional way for the preparation of magnetite. However, the reaction process should be carried out under nitrogen to prevent further oxidation to hematite. In this work, the whole process was achieved under normal conditions in the absence of nitrogen. The aim of using the ferrous salt was to induce the formation of traces of magnetic phase product, which was confirmed from the XRD, Raman spectra, and magnetization measurements. Coating of iron oxide was achieved using different weights percent $(0.5,1.5$, and 2) of chitosan (CS) (MALLINCKRODT, France) dissolved into $10 \%$ acetic acid solution. Then the mixture was moved to the autoclave and heated at $160{ }^{\circ} \mathrm{C}$ for $30 \mathrm{~h}$. The produced samples were centrifuged, washed by ethanol, and distilled water several times, then dried at $70{ }^{\circ} \mathrm{C}$ and coded $\mathrm{HC} 0.5, \mathrm{HC} 1.5$, and $\mathrm{HC} 2$, respectively.

\subsection{Characterization.}

X-ray diffraction was obtained using $\mathrm{X}^{\prime}$ pert pro. PANalytical, Holland using $\mathrm{Cu} \mathrm{K} \alpha$

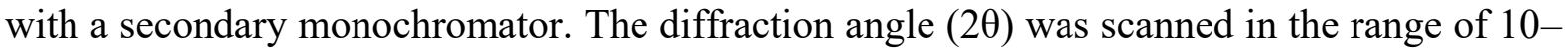
$80^{\circ}$ for phase identification. Transmission electron microscopy (HR TEM-JEM 2100, JEOL, Japan) operating at $200 \mathrm{kV}$ accelerating voltage was utilized to study the shape and particle size. Using an ultrasonic water bath, a suspension of the sample powder in absolute ethanol was obtained, then a drop of this suspension was put onto a carbon grid and left to dry. The infrared (IR) spectra were obtained in the ranges (400-4000) $\mathrm{cm}^{-1}$ using a JASCO spectrometer (FT/IR-6300 type A). The Raman measurement was carried out with dispersive Raman spectroscopy at laser $785 \mathrm{~nm}$ and laser power $0.10 \mathrm{MW}$, Senterra, Bruker Optics, Germany.

The magnetic properties were evaluated by the vibrating sample magnetometer (VSM LakeShore 7410). The magnetization hysteresis was acquired by fluctuating $\mathrm{H}$ between +20000 Oe and -20000 Oe. Dielectric parameters were recorded in the temperature range $\left(25-80^{\circ} \mathrm{C}\right)$ and frequency range (100 HZ-5 MHZ) using HIOKI Japan 3532-50 LCR HI TESTER.

\subsection{Cell lines and culture.}

Anticancer activity of the HC nanocomposites was evaluated against four human cancer cells: liver HepG2, breast MCF-7, colon HCT116, and lung A549 (American Type Culture Collection (Rockville, MD, USA). The tumor cells were sustained in Dulbecco's modified Eagle's medium (DMEM) supplemented with $10 \%$ heat-inactivated fetal calf serum (GIBCO), penicillin $(100 \mathrm{U} / \mathrm{ml})$, and streptomycin $(100 \mu \mathrm{g} / \mathrm{ml})$ at $37{ }^{\circ} \mathrm{C}$ in a humidified atmosphere containing $5 \% \mathrm{CO}_{2}$. Cells at a concentration of $0.50 \times 10^{6}$ were grown in a $25 \mathrm{~cm}^{2}$ flask in 5 $\mathrm{ml}$ of complete culture medium.

\subsection{In vitro antiproliferative assay.}

The antiproliferative activity was measured in vitro using (MTT) assay according to the previously reported standard procedure[24]. Cells were inoculated in a 96-well microtiter plate $\left(10^{4}\right.$ cells/ well $)$ for $24 \mathrm{~h}$ before treatment with the tested compounds to allow attachment of the cell to the wall of the plate. DMSO was used to dissolve the tested materials then diluted with saline to the appropriate volume. Different concentrations of the HC nanocomposites (0$500 \mu \mathrm{g} / \mathrm{ml}$ ) were added to the cells. Results were obtained by preparation triplicate wells for each individual dose. Monolayer cells were incubated with the $\mathrm{HC}$ nanocomposites in an atmosphere of $5 \% \mathrm{CO}_{2}$ for $48 \mathrm{~h}$ at $37{ }^{\circ} \mathrm{C}$ and. Hereafter, the media were removed and $40 \mu \mathrm{l}$ MTT solution was added for each well and incubated for extra 4 hours. $200 \mu$ l of DMSO were 
added to each well to solubilize the MTT crystals by shaking the well gently for $10 \mathrm{~min}$ at room temperature. The survival curve for each cell line after the specified time and the concentration required for $50 \%$ inhibition of cell viability (IC50) were calculated by measuring the absorbance with a microplate reader (AsysHitech, Austria) at $570 \mathrm{~nm}$.

\subsection{Statistical analysis.}

Four times experiments were carried out at least and the results were recorded as a Mean \pm Standard error (S.E.). Statistical significances were examined using one way ANOVA test followed by student's $t$-test, differences at $p<0.05$ were considered significant.

\section{Results and Discussion}

\subsection{XRD analysis.}

XRD pattern of pure chitosan (Figure 1) displays a characteristic crystalline peak at $2 \theta$ value $20^{\circ}$. Duan attributed this peak to the ability of chitosan molecules to form crystalline form easily due to the presence of amply of $-\mathrm{OH}$ and $-\mathrm{NH}_{2}$ groups in the chitosan structure, allowing it to form strong inter and intramolecular hydrogen bonds and imparting the chitosan structure a certain kind of regularity [25]. However, as regards HC composites, this characteristic peak disappeared.

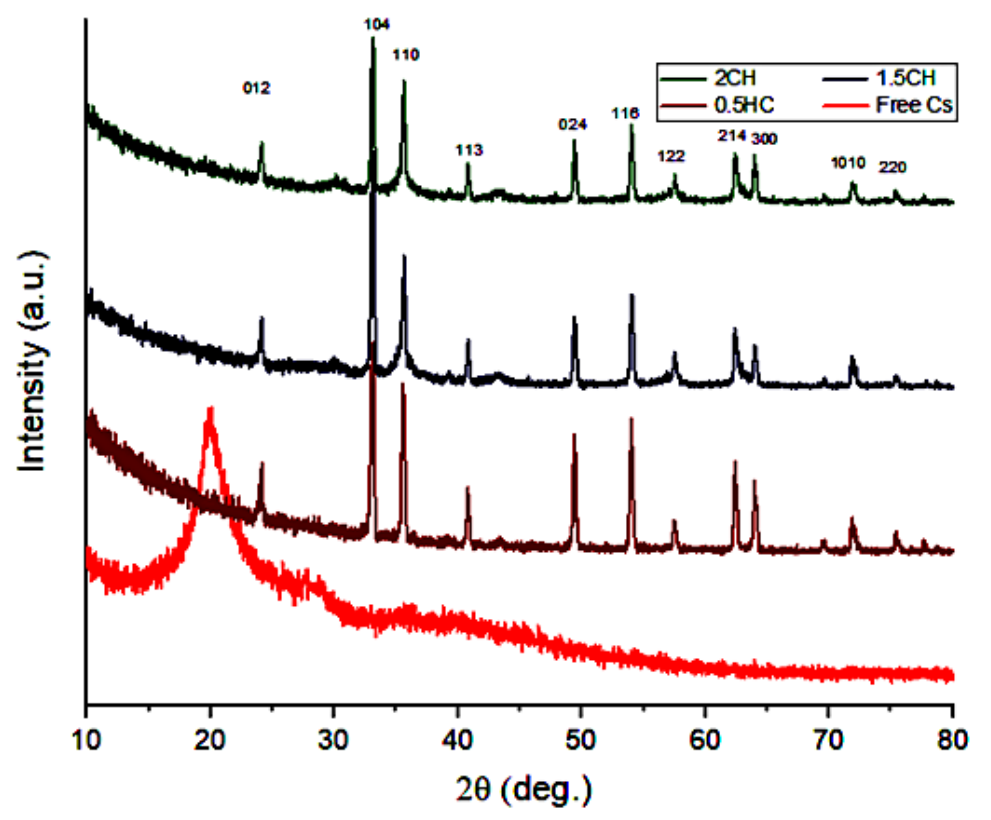

Figure 1. XRD patterns of Pure CS, HC0.5, HC1.5 and HC2 nanocomposites.

The reason may attribute to the destruction of the intermolecular hydrogen bonds and the crystalline regions of chitosan, which indicate a good linking of $\alpha-\mathrm{Fe}_{2} \mathrm{O}_{3}$ nanoparticles into the main chitosan chains. XRD patterns of $\mathrm{HC}$ nanocomposites exhibit a typical $\alpha-\mathrm{Fe}_{2} \mathrm{O}_{3}$ structure where eleven characteristic peaks are observed for $\alpha-\mathrm{Fe}_{2} \mathrm{O}_{3}$ nanoparticles $\left(2 \theta=24.1^{\circ}\right.$, $33.1^{\circ}, 35.6^{\circ}, 40.7^{\circ}, 49.4^{\circ}, 54.0^{\circ}, 57.4^{\circ}, 62.3^{\circ}, 63.9^{\circ}, 71.8^{\circ}$ and $\left.75.3^{\circ}\right)$ marked by their indices ((012), (104), (110), (113), (024), (116), (018), (214), (300), (1010) and (220), respectively) and the Bragg lines are listed in the R3c space group with the hexagonal sitting. The diffraction peaks and lattice parameters of the synthesized $\alpha-\mathrm{Fe}_{2} \mathrm{O}_{3}$ are in perfect agreement with those 
stated in the typical reference data [COD ID 9000139]. The XRD pattern reveals the presence of less intense peaks for maghemite [COD ID 900-6317] and magnetite [COD ID 900-5842]. The Semi-quantitative analysis (SQA) based on (Reference Intensity Ratio method) is 85.6: 12.4: 2.0 hematite, maghemite, and magnetite phases, respectively. It was noticed that the peaks become less intense and broader with increasing the amount of chitosan from 0.5 to 2.0 wt $\%$. However, the diffraction spectra preserved their good crystallinity upon coating, these findings have been supported with the TEM images that show that the surface of $\alpha-\mathrm{Fe}_{2} \mathrm{O}_{3}$ nanoparticles is subjected to only a thin layer coating of chitosan. The crystallographic parameters ( $\mathrm{a}$ and $\mathrm{c}$ ) hexagonal settings of the produced compounds are resolved using the smallest square fits (Table 1). The crystallographic data show similar values for all three samples clarifying that the coating process does not influence the lattice parameters, crystal shape, and cell volume.

\subsection{TEM analysis.}

TEM images of HC0.5, HC1.5, and HC2 (Figure 2a-c, respectively) show that the prepared magnetic nanoparticles have regular external hexagonal shapes with an average diameter in the 7-11 nm range with some aggregation. Based on the data obtained from TEM, it is clear that the chosen technique to coat the nanoparticles has not a significant influence on the particle size, which discards the particle size dependency on the CS: $\alpha-\mathrm{Fe}_{2} \mathrm{O}_{3}$ ratio, although it contributes to the aggregation state of the nanoparticles. The images reveal a uniform dispersion of $\alpha-\mathrm{Fe}_{2} \mathrm{O}_{3}$ nanoparticles inside the CS matrix with some aggregation. The chitosan component appears as sheets surround and successfully coat the $\alpha-\mathrm{Fe}_{2} \mathrm{O}_{3}$ nanoparticles.

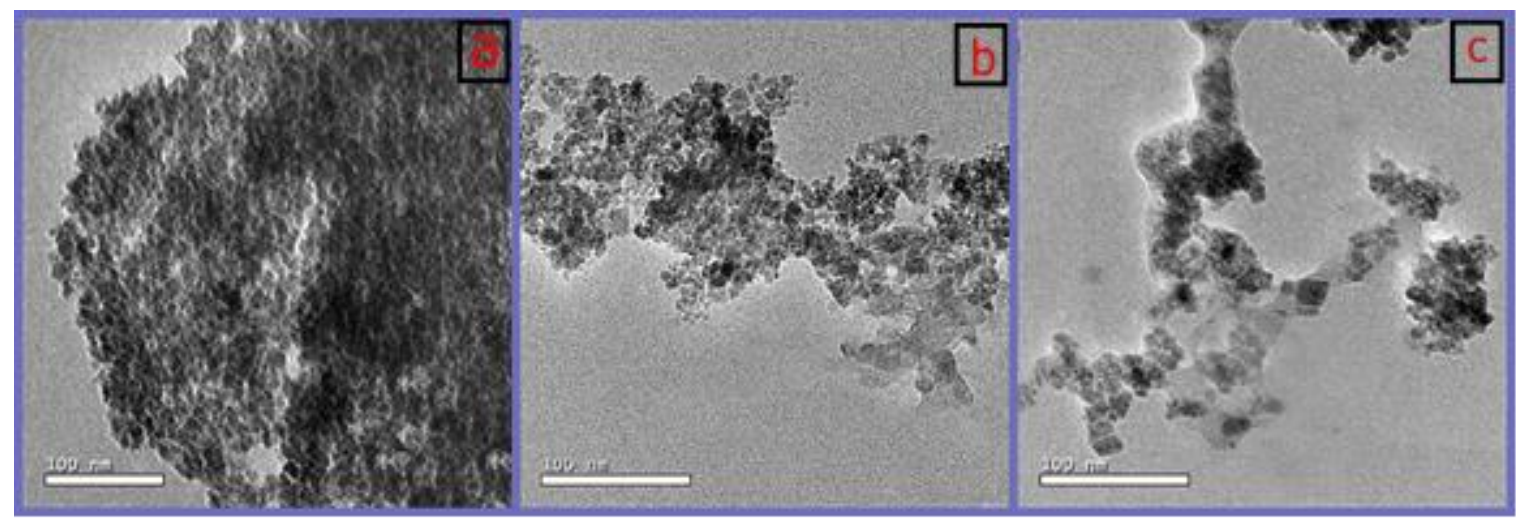

Figure 2. TEM images of (a) HC0.5; (b) HC1.5; (c) HC2.

Table 1. XRD and TEM data obtained for HC0.5, HC1.5 and $\mathrm{HC} 2$.

\begin{tabular}{l|c|c|c|c|c} 
Composites & $\mathbf{a} \AA$ & $\mathbf{c} \AA$ & $\mathbf{v A}^{\mathbf{3}}$ & Crystal shape & particle size, $\mathbf{n m}$ \\
\hline HC0.5 & 5.04 & 13.77 & 302.72 & Hexagonal & $8.0-10.0$ \\
\hline HC1.5 & 5.04 & 13.77 & 302.72 & Hexagonal & $7.0-11.0$ \\
\hline HC2 & 5.04 & 13.77 & 302.72 & Hexagonal & $7.0-11.0$
\end{tabular}

\subsection{FT-IR.}

FTIR spectrum of pure CS (Figure 3d) shows the characteristic absorption bands for pure chitosan, which appear at 3430 (O-H stretching vibrations), 3330 ( N-H stretching vibrations), 2925 (C-H stretching vibrations), 1650 ( $\mathrm{NH}$ bending indicating the presence of $\mathrm{N}$ acetyl amino group), 1597 ( $\mathrm{N}-\mathrm{H}_{2}$ bending vibrations), 1154 (C-O-C bridge stretching) and $1077 \mathrm{~cm}^{-1}$ (C-O stretching vibrations) [26,27]. 
Spectral data of $\mathrm{HC} 0.5, \mathrm{HC} 1.5$, and $\mathrm{HC} 2$ samples (Figure 3a-c) reveal the existence of peaks distinctive to $\mathrm{CS}$ and iron oxide. The existence of $\alpha-\mathrm{Fe}_{2} \mathrm{O}_{3}$ nanoparticles core can be proved by the intense absorption peaks characteristic to the $\mathrm{Fe}-\mathrm{O}$ bond around 560 and 475 $\mathrm{cm}^{-1}$. The IR spectral data also revealed bands around 3400, 1630 and $1075 \mathrm{~cm}^{-1}$ belonging to $\mathrm{O}-\mathrm{H}$ stretching, $\mathrm{N}-\mathrm{H}$ bending and $\mathrm{C}-\mathrm{O}$ stretching vibrations, respectively (Table 2). These findings prove that $\alpha-\mathrm{Fe}_{2} \mathrm{O}_{3}$ nanoparticles are successfully coated by the CS polymer. It worth noting that the band corresponding to $\mathrm{N}-\mathrm{H}_{2}$ bending of pure chitosan was disappeared in $\alpha$ $\mathrm{Fe}_{2} \mathrm{O}_{3} / \mathrm{CS}$ hybrid nanocomposites samples while the bands corresponding to $\mathrm{N}-\mathrm{H}$ bending and $-\mathrm{NH} / \mathrm{OH}$ stretching modes are subject to shifts and a decrease in the intensity. This indicates that the cationic biopolymer matrix of chitosan is attached to the surface of charged iron oxide nanoparticles through electrostatic interaction and hydrogen bonding [17,28].

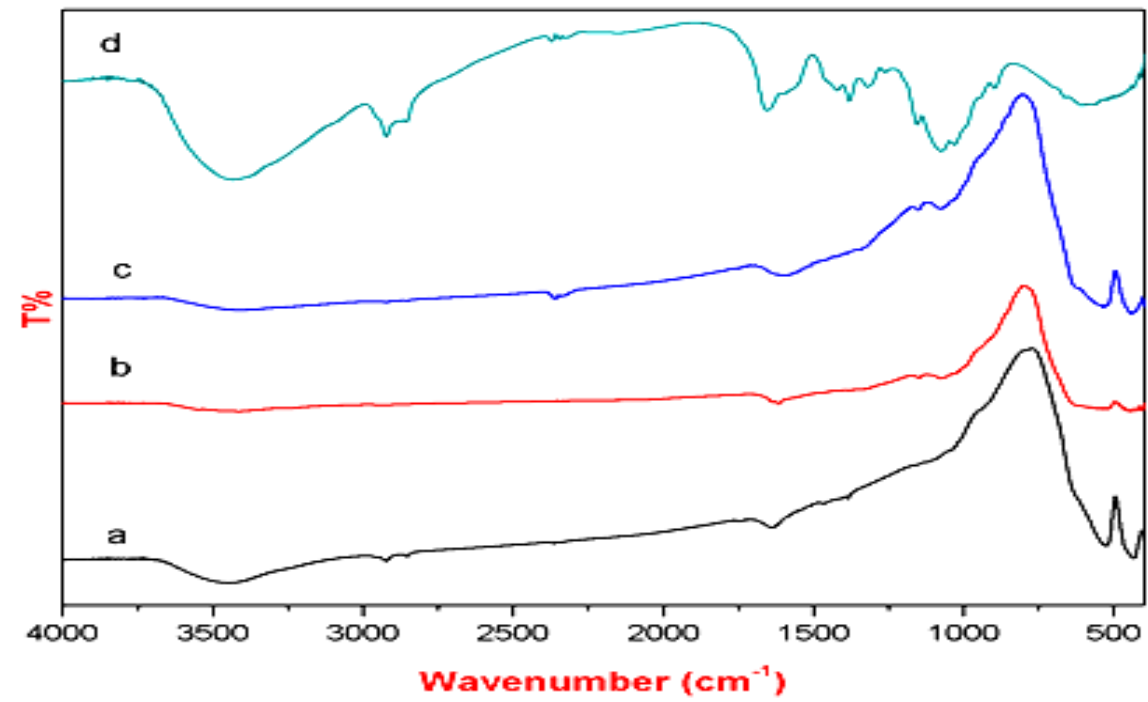

Figure 3. FTIR spectra of (a) $\mathrm{HC} 0.5$; (b) $\mathrm{HC} 1.5$; (c) $\mathrm{HC} 2$; (d) Pure CS.

Table 2. IR assignments of HC0.5, HC1.5, HC2 and Pure CS.

\begin{tabular}{l|c|c|c|c} 
Bond position (wavenumber $\mathbf{~ m}^{-1}$ ) & HC0.5 & HC1.5 & HC2 & Pure CS \\
\hline $\mathrm{O}-\mathrm{H}_{\text {stretching }(\mathrm{H} \text { bonded }}$ & 3450 & 3404 & 3407 & 3430 \\
\hline $\mathrm{N}-\mathrm{H}_{\text {stretching }}$ & - & - & - & 3330 \\
\hline $\mathrm{C}-\mathrm{H}_{\text {stretching }}$ & 2922 & - & - & 2925 \\
\hline $\mathrm{N}-\mathrm{H}_{\text {bending }}$ & 1636 & 1616 & 1593 & 1650 \\
\hline $\mathrm{C}-\mathrm{O}-\mathrm{C}_{\text {stretching }}$ & - & 1146 & 1150 & 1154 \\
\hline $\mathrm{C}-\mathrm{O}_{\text {stretching }}$ & - & 1077 & 1076 & 1077 \\
\hline $\mathrm{M}-\mathrm{O}_{\text {stretching at the tetrahedral- site }}$ & 525 & 564 & 534 & - \\
\hline $\mathrm{M}-\mathrm{O}_{\text {stretching at the octahedral- site }}$ & 432 & 436 & 445 & -
\end{tabular}

\subsection{Raman spectra.}

The prepared HC nanocomposites were also characterized by Raman spectroscopy to identify expected iron oxide phases present in the sample. The XRD pattern indicates the presence of traces of maghemite and magnetite. The Raman spectrum (Figure 4) clearly shows the presence of five peaks at 213,288, 402, 495, and $611 \mathrm{~cm}^{-1}$ distinctive to the hematite phase. The presence of maghemite and magnetite was revealed by the appearance of one peak at 702 $\mathrm{cm}^{-1}$ and two peaks at 525 and $660 \mathrm{~cm}^{-1}$, respectively. There is also a redshift of the Raman lines, which is common for nanoparticles [29]. 


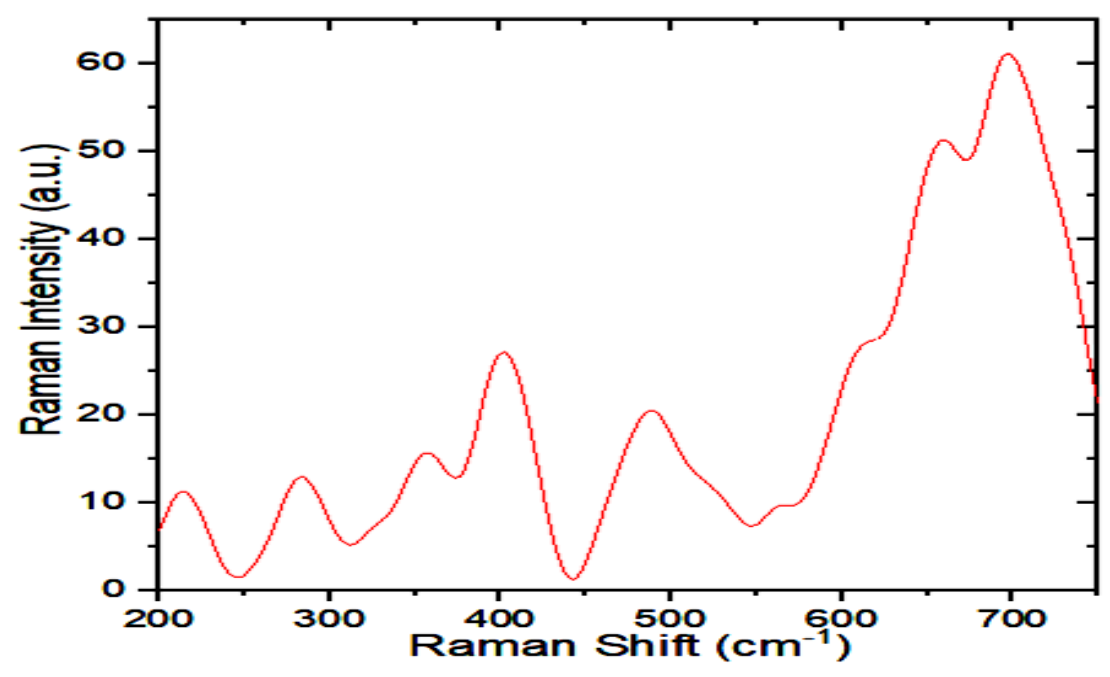

Figure 4. Raman spectrum of HC1.5.

\subsection{Magnetic properties.}

Figure 5 shows the magnetization curves at room temperature of the prepared samples. The response variables characterizing the magnetic behavior of the nanocomposites showed that the saturation magnetization $\left(\mathrm{M}_{\mathrm{s}}\right)$ of the prepared samples decreases with increasing the amount of chitosan polymer. The saturation magnetization decline is attributed to the presence of non-magnetic carbon residue around the nanoparticle core, which in turn is related to the shell content. Similar findings were reported on a coating of magnetite by Cuong, who attributed a decrease in the saturation magnetization of the pristine $\mathrm{Fe}_{3} \mathrm{O}_{4}$ nanoparticles $(76.68$ $\mathrm{emu} / \mathrm{g})$, upon coating with chitosan $(60 \mathrm{emu} / \mathrm{g})$ to a large amount of diamagnetic chitosan present [30]. The higher the chitosan: magnetic nanoparticles ratio, the lower the saturation magnetization of the nanocomposite. Although the TEM findings showed a successful coating of the nanoparticles, the chitosan layer is so small to completely obscure magnetization detection. Recalling in this respect, the higher saturation values of our nanocomposite samples, although being coated with chitosan, than that reported by the majority of literature related to $\alpha-\mathrm{Fe}_{2} \mathrm{O}_{3}$ [31-33]. The reason for such remarkable high magnetization values can be described by specific effects of the multilevel hierarchical arrangement of the hematite structure. The small particle size with dimensions less than $11 \mathrm{~nm}$, as shown in TEM images (7-11 nm), plays a crucial role in this behavior; the high magnetization of these small particles size could be assigned to the involvement of uncompensated surface spins, which tend to interact ferromagnetically[12]. Another major factor is the tendency of nano-sized particles to accumulate, leading to cluster assembly (observed as apparent aggregations in the TEM images), leading to magnetization enhancement. Similar findings were reported for magnetite by $\mathrm{Ge}$ et al. who illustrated that large size clusters of magnetite demonstrate higher values of magnetization than isolated clusters. He related this behavior to the interaction of large clusters to the production of structures with different hierarchical levels (with larger sizes), leading to enhancing the magnetization value [34]. From another point of view, the presence of traces of iron oxide phases (magnetite and maghemite) other than hematite (deduced from the XRD and Raman spectra) can also participate in strengthing the magnetization of its domains or increase their tendency to stay stuck once they are lined up [35]. As can be seen from figure 5, there is almost no hysteresis in the HC0.5 sample, so both the coercivity and remanent magnetization $\left(\mathrm{M}_{\mathrm{r}}\right)$ values are low. These indicate a typical superparamagnetic behavior; when the particle size is reduced below a critical value, a single crystal will become a single domain[36]. The 
coercivity $(\mathrm{Hc})$ values and the remanent magnetization showed a small gradual increase upon increasing the non-magnetic chitosan content Table (3). Yet, the values of the coercivity $\left(\mathrm{H}_{\mathrm{c}}\right)$ and the remanent magnetization $\left(\mathrm{M}_{\mathrm{r}}\right)$ are lower than those reported for pure $\alpha-\mathrm{Fe}_{2} \mathrm{O}_{3}$ nanoparticles [31-33]. These findings are promising for exploiting these samples in the biomedical field.

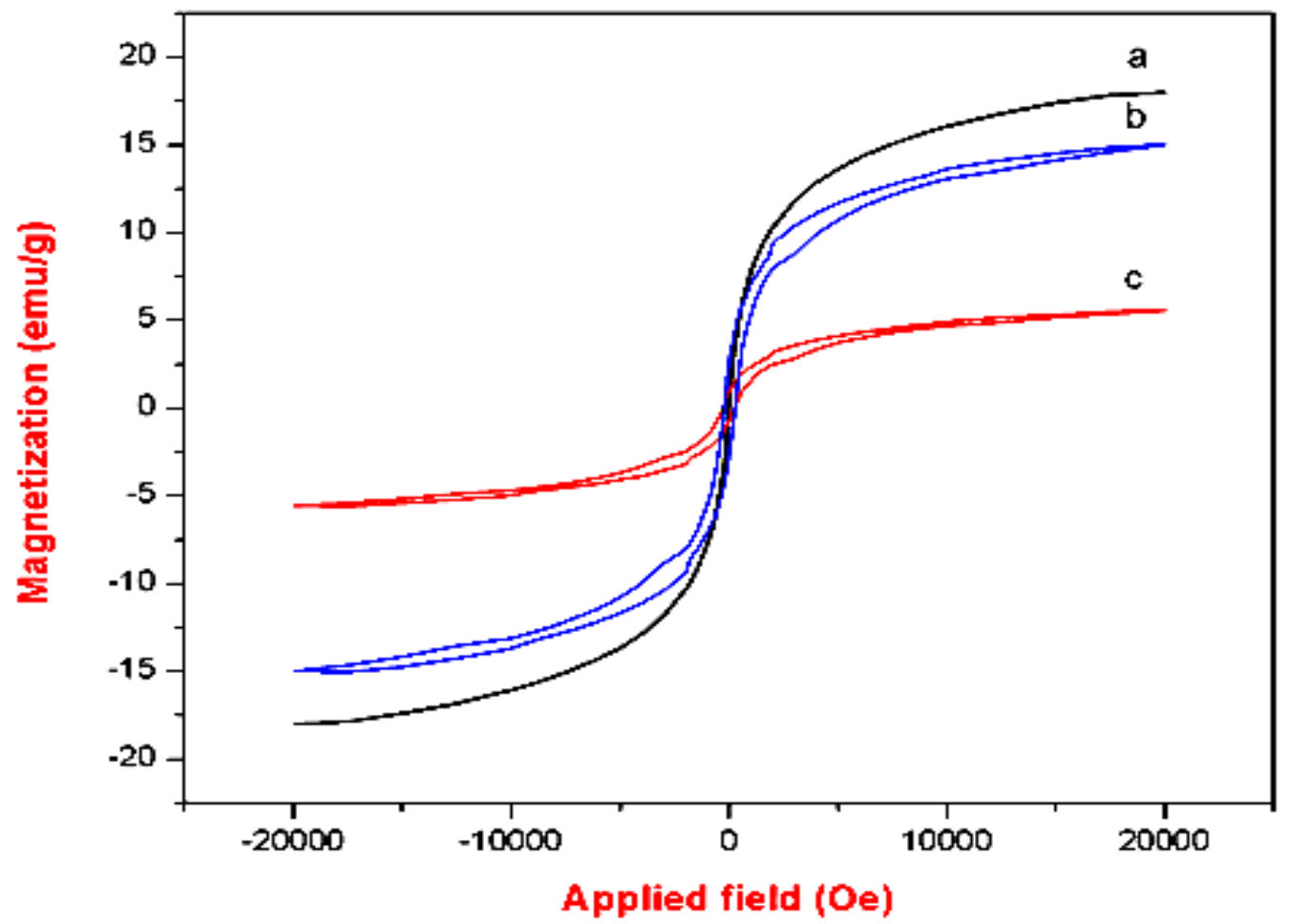

Figure 5. VSM of (a) HC0.5; (b) HC1.5; (c) HC2.

Table 3. Magnetic parameters of $\mathrm{HC} 0.5, \mathrm{HC} 1.5$ and $\mathrm{HC} 2$.

\begin{tabular}{l|c|c|c} 
Compound & \multicolumn{3}{|c}{ Magnetic parameters } \\
\hline HC0.5 & $\mathbf{M}_{\mathbf{s}}(\mathbf{e m u} / \mathbf{g})$ & $\mathbf{H}_{\mathbf{c}}(\mathbf{O e})$ & $\mathbf{M}_{\mathbf{r}}$ \\
\hline HC1.5 & 18 & 15.6 & 0.228 \\
\hline HC2 & 15 & 19.4 & 0.241 \\
\hline & 5.6 & 68.6 & 0.224
\end{tabular}

3.6. Electrical properties.

The dielectric constant, ' $\varepsilon$ ' can be decided from capacitance by utilizing Eq. (1)

$$
\varepsilon^{\prime}=\mathrm{CL} / \varepsilon_{0} \mathrm{~A}
$$

where ' $\mathrm{C}$ ' is the capacitance, ' $\mathrm{L}$ ' the sample thickness, ' $\varepsilon_{\mathrm{o}}$ ' the permittivity of air $\left(8.85 \times 10^{-12}\right.$ $\mathrm{Fm}^{-1}$ ) and ' $\mathrm{A}$ ' is the area of cross-section of samples.

The frequency dependence of dielectric constant $\left(\varepsilon^{\prime}\right)$ and dielectric loss $\left(\varepsilon^{\prime \prime}\right)$ at different temperatures for $\mathrm{HC} 0.5, \mathrm{HC} 1.5$, and $\mathrm{HC} 2$ in the frequency range $100 \mathrm{~Hz}-5 \mathrm{MHz}$ are shown in Figures $6 \mathrm{a}-\mathrm{c}$ and $7 \mathrm{a}-\mathrm{c}$. It can be noticed that both dielectric constant and dielectric loss for all the samples present a relatively high value at the low-frequency range and gradually decrease with increasing the frequency and almost remain independent of the applied external field at the high-frequency division. This behavior can be attributed to that; at a lower frequency, the dipoles in the system can reorient themselves to respond to the applied electric field. Whereas at higher frequencies, the decrease of both dielectric constant and dielectric loss values is attributed to the lag of molecules towards the applied electric field and this can be explained by the difficulty of dipoles orientation in this frequency range. 
The constant dielectric increases with increasing temperature in the case of HC2 and $\mathrm{HC} 1.5$, but in the case of $\mathrm{HC} 0.5, \varepsilon^{\prime}$ decreases at $70{ }^{\circ} \mathrm{C}$. This rise may be because of the thermal energy provided to the material that is adequate to release the restricted dipoles. They line up themselves in the path of the applied field. On the other hand, the dielectric loss rises with rising temperature in the case of $\mathrm{HC} 2$ and $\mathrm{HC} 1.5$, but in the case of $\mathrm{HC} 0.5, \varepsilon^{\prime \prime}$ decreases at $60{ }^{\circ} \mathrm{C}$. This increase may be ascribed to rising lattice vibrations and creating some phonons that interact with the charge carriers resulting in electron-phonon scattering [37].

The $\left(\varepsilon^{\prime}\right.$ and $\left.\varepsilon^{\prime \prime}\right)$ values increased with CS loading in composites as shown in Table 4, since the dipole increases as the weight percentage of CS rises in the matrix. This observed increment in $\left(\varepsilon^{\prime}\right.$ and $\left.\varepsilon^{\prime \prime}\right)$ values had been ascribed to the rise in orientation and interfacial polarization arising from still existence of free polar $\mathrm{NH}^{3+}$ ions in chitosan [38].
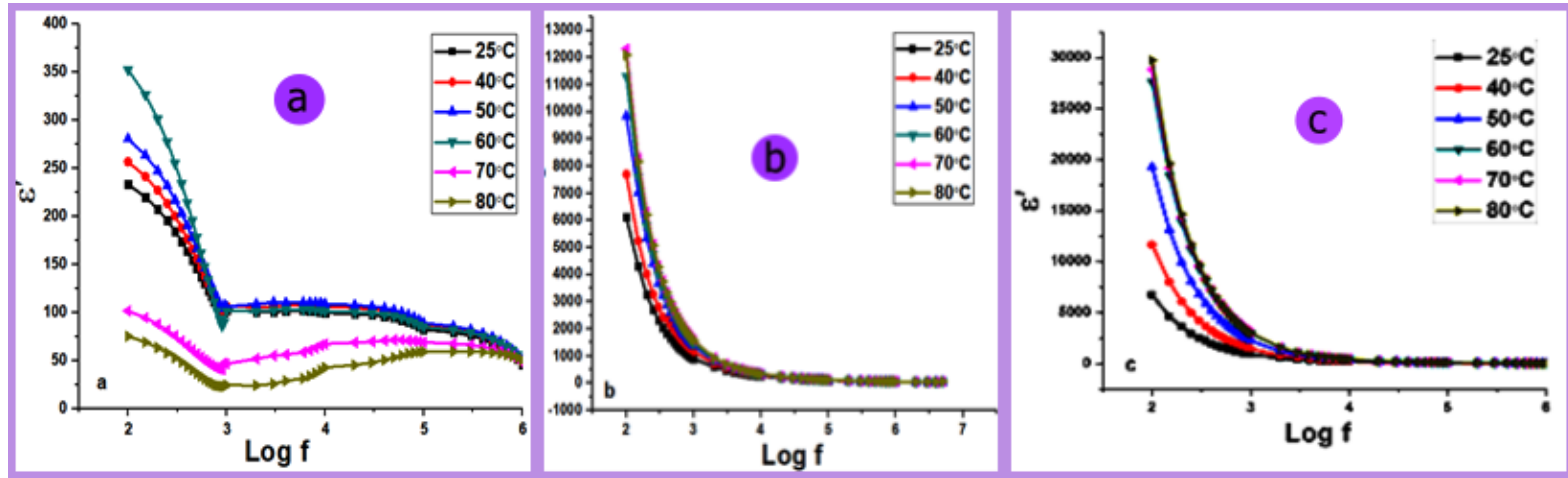

Figure 6. Variation of dielectric constant with frequency at different temperatures for (a) HC0.5; (b) HC1.5; (c) HC2.
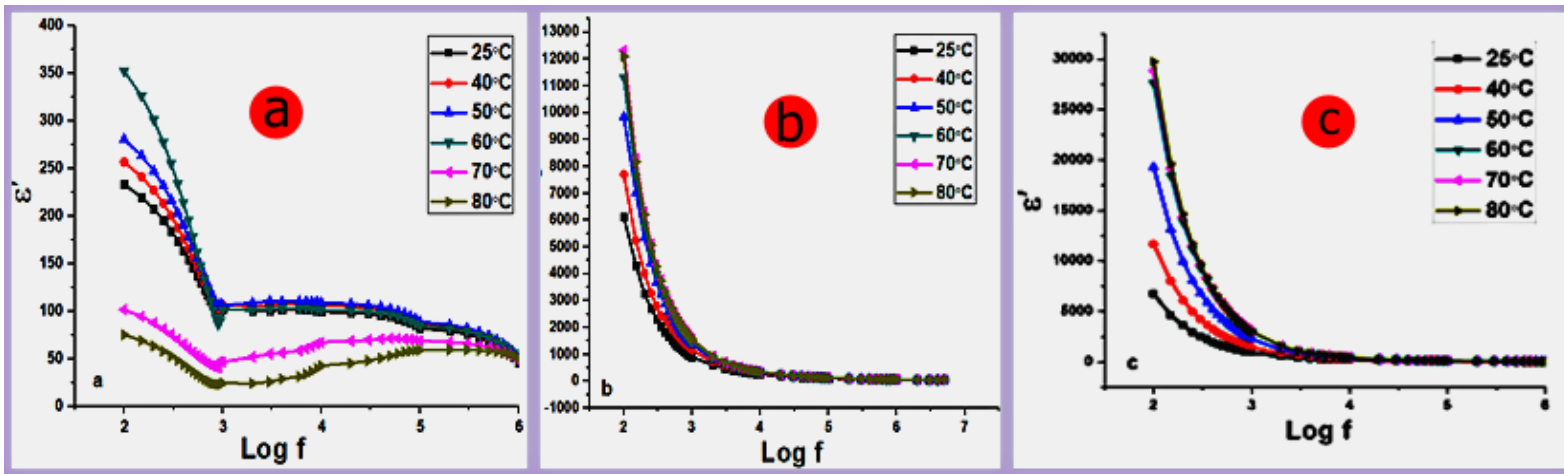

Figure 7. Variation of dielectric loss with frequency at different temperatures for (a) $\mathrm{HC} 0.5$; (b) $\mathrm{HC} 1.5$; (c) $\mathrm{HC} 2$.

\subsection{Biological evaluation.}

The antiproliferative activity of the produced compounds is estimated against four human cancer cell lines: breast MCF-7, liver HepG2, lung A549, and colon HCT116 utilizing MTT assay and doxorubicin as a standard drug. The results reveal that all the compounds do not apply any activity versus human breast cancer MCF-7 and lung cancer A549 cell lines. The median growth inhibitory concentration $\left(\mathrm{IC}_{50}\right)$ values are calculated for the samples and results are offered in Table 5. It is seen that the tumor cell lines show usual progress in our culture system and DMSO does not appear to have any remarkable influence on cellular growth. It is interestingly found that $\mathrm{HC} 0.5, \mathrm{HC} 1.5$, and $\mathrm{HC} 2$ display powerful growth inhibitory activity versus both human hepatocellular carcinoma HepG2 and human colon cancer HCT116 cell 
lines. The $\mathrm{IC}_{50}$ of the tested compounds $\mathrm{HC} 0.5, \mathrm{HC} 1.5$, and $\mathrm{HC} 2$ for HepG2 cell line is $30.70 \pm 3.33,27.00 \pm 2.80$ and $22.00 \pm 3.00 \mu \mathrm{g} / \mathrm{ml}$ respectively, it is obvious that HC2 has IC50 value closed to the value of the standard drug, doxorubicin $(20.10 \pm 2.00 \mu \mathrm{g} / \mathrm{ml})$. Similarly, for the colon HCT116 cell line, the $\mathrm{IC}_{50}$ of the compounds is $26.00 \pm 2.80,23.77 \pm 2.40$, and $21.00 \pm 2.50 \mu \mathrm{g} / \mathrm{ml}$ respectively, it is clear that $\mathrm{HC} 2$ has $\mathrm{IC}_{50}$ value closed to the value of the standard drug, doxorubicin $(19.25 \pm 2.00 \mu \mathrm{g} / \mathrm{ml})$. The development in the cytotoxicity activity can be ascribed to either that the polycationic character of chitosan overlaps with the negatively charged residues of macromolecules at the cell surface and changed cell permeability, or the DNA binding capability of cationic chitosan that give rise to the hindrance of RNA synthesis [17,39]. It can be viewed that the anticancer activity rises with the increase in CS loading, whereas IC50 values decrease with increasing CS content, as shown in Table 4. This is due to the charge density $\left(\mathrm{NH}_{3}{ }^{+}\right)$increases with the rise in the CS content that is likewise noticed in dielectric studies [38]. Nevertheless, It is important to refer that chitosan itself records a feeble anticancer activity on human hepatocellular carcinoma HepG2 and human colon cancer HCT116 cell lines with $\mathrm{IC}_{50}=260.00 \pm 25.70$ and $290.60 \pm 30.80 \mu \mathrm{g} / \mathrm{ml}$, respectively. This value has been diminished distinctly and became so adjacent to the value of the standard drug, doxorubicin, signifying better cytotoxicity activity upon its combining with iron oxide. This verdict can be associated with that the great chelating capability of chitosan to bind to the metal ions in iron oxide samples causes a rise in the number of its active hydroxyl and amino groups that may share in free radical prowling donated to the antitumor activity [40]. This noticeable binding capability is for the reason that i) chitosan has a great number of hydroxyl groups and primary amino groups with great activity as binding sites. ii) the polymer chain of chitosan supplies a flexible structure that is deliberated appropriate configuration for complexation with metal ions $[17,41,42]$.

Taken together, the above-mentioned results recommend that the prepared compounds apply anti-carcinogenic activity through the reduction of cell proliferation and cause an important growth inhibitory. Moreover, the current study reveals that HepG2 cells are more sensitive to the tested compounds than HCT116 cancer cells. It is worth mentioning that there is some correlation between the anticancer activity and dielectric character samples (table 4). The dielectric studies disclosed the significant role of amino groups of chitosan that can furnish $\mathrm{NH}_{3}{ }^{+}$ions. These positive ions can interact with the negatively charged cell walls of cancer cells and hinder the progress of cancer cells [38]. The anticancer activity of the tested composites is following their dielectric behavior. This correlation will be helpful for the assessment of anticancer activity of HC biocomposites.

Table 4. The values of $\varepsilon^{\prime}$ and $\varepsilon^{\prime \prime}$ at room temperature and frequency $1 \mathrm{KHz}$ and $\mathrm{IC}_{50}(\mu \mathrm{g} / \mathrm{ml})$ of the tested compounds against HepG2 and HCT116 cell lines.

\begin{tabular}{ccccc}
\hline Composites & $\boldsymbol{\varepsilon}^{\prime}$ & $\boldsymbol{\varepsilon}^{\prime \prime}$ & \multicolumn{2}{c}{ IC $_{\mathbf{5 0}}$} \\
\cline { 3 - 5 } & & & HepG2 cell line & HCT116 cell line \\
\hline HC0.5 & 80.2 & 91.7 & $30.70 \pm 3.33$ & $26.00 \pm 2.80$ \\
\hline HC1.5 & 892.2 & 3515.6 & $27.00 \pm 2.80$ & $23.77 \pm 2.40$ \\
\hline HC2 & 927.99 & 4034.8 & $22.00 \pm 3.00$ & $21.00 \pm 2.50$ \\
\hline
\end{tabular}

Table 5. Cytotoxicity $\left(\mathrm{IC}_{50}, \mu \mathrm{g} / \mathrm{ml}\right)$ of the tested compounds against human malignant cell lines using MTT assay method*.

\begin{tabular}{ccccc}
\hline \multirow{2}{*}{ Compounds } & \multicolumn{4}{c}{ Cell line } \\
\cline { 2 - 5 } & HepG2 & MCF-7 & A549 & HCT116 \\
\hline Doxorubicin & $20.10 \pm 2.00$ & $24.00 \pm 2.50$ & $25.50 \pm 2.70$ & $19.25 \pm 2.00$ \\
\hline DMSO & NA** $^{* *}$ & NA & NA & NA \\
\hline Pure CS & $260.00 \pm 25.70$ & NA & NA & $290.60 \pm 30.80$ \\
\hline
\end{tabular}




\begin{tabular}{ccccc}
\hline \multirow{2}{*}{ Compounds } & \multicolumn{5}{c}{ Cell line } \\
\cline { 2 - 5 } & HepG2 & MCF-7 & A549 & HCT116 \\
\hline HC0.5 & $30.70 \pm 3.33$ & NA & NA & $26.00 \pm 2.80$ \\
\hline HC1.5 & $27.00 \pm 2.80$ & NA & NA & $23.77 \pm 2.40$ \\
\hline HC2 & $22.00 \pm 3.00$ & NA & NA & $21.00 \pm 2.50$ \\
* Data were expressed as means \pm S.E. of four separate experiments. \\
**NA = No activity
\end{tabular}

\section{Conclusions}

HC nanocomposites were synthesized in situ by a hydrothermal process. XRD patterns and TEM micrographs indicated that the synthesized nanocomposites have a spherical core with a cubic spinel structure successfully coated with sheets of chitosan and have a mean diameter in the 7-11 nm range. The saturation magnetization $\left(\mathrm{M}_{\mathrm{s}}\right)$ of $\mathrm{HC} 0.5, \mathrm{HC} 1.5$, and $\mathrm{HC} 2$ recorded high values at room temperature, signifying a superparamagnetic behavior that decreases with increasing the amount of chitosan. On the other hand, the coercivity $\left(\mathrm{H}_{\mathrm{c}}\right)$ and the remanent magnetization values showed a small gradual increase in the non-magnetic chitosan content. The dielectric constant and loss values decreased with increasing frequency. The maximum values of dielectric constant and loss at the lower frequency region have been attributed to the interfacial polarization. An increment in dielectric constant and loss of composites with chitosan loading was due to the increased orientation and interfacial polarization. In vitro antiproliferative activity, estimation declared that the $\mathrm{HC}$ nanocomposites display powerful growth inhibitory activity against human hepatocellular carcinoma HepG2 and human colon cancer HCT116 cell lines, very close to the value of the standard drug, doxorubicin. Our results strongly suggest that $\mathrm{HC}$ nanocomposites reserve more investigation as anticancer chemotherapeutic agents. Our study also clarifies a possible correlation between the anticancer activity of $\mathrm{HC}$ nanocomposites and their dielectric properties that can be used to predict the possible bioactivity of 2 nanocomposites.

\section{Acknowledgments}

\section{Authors thank National Research Centre, Egypt, for providing funds to carry out this research} work.

\section{Conflicts of Interest}

The authors declare no conflict of interest.

\section{References}

1. Liu, G.; Li, L.; Yang, X. Preparation of ellipsoidal hematite/polymer hybrid materials and the corresponding hollow polymer ellipsoids. Polymer 2008, 49, 4776-4783, http://dx.doi.org/10.1016/j.polymer.2008.08.043.

2. García-Martínez, J.-M.; Collar ,E.P. Organic-Inorganic Hybrid Materials. Polymers 2021, 13, https://doi.org/10.3390/polym13010086 .

3. Hussien, H.A.J.; Kadhim, R.G.; Hashim, A. Synthesis and Properties of Novel (Organic Material-Inorganic Nanoparticles) System for New Pressure Sensors. In Proceedings of the Journal of Physics: Conference Series 2021; 012119, https://doi.org/10.1088/1742-6596/1818/1/01211.

4. Mandava, K.; Uma Rajeswari, B. Fabrication and Functionalization of Other Inorganic Nanoparticles and Nanocomposites. Functionalizd Nanomaterials $\quad$ I: $\quad$ Fabrications $\quad 2020, \quad 239$, https://doi.org/10.1201/9781351021623 ..16-

5. Wahba, M.A.; El-Saied, F.A.; Al-Hakimi, A.N.; Shakdofa, M.M. Preparation, Characterization and Antimicrobial Activities of N'-((3-(hydroxyimino) butan-2-ylidene)-2 (phenylamino) acetohydrazide and Its Metal Complexes. Egyptian Journal of Chemistry 2017, 60, 1-24. 
6. Fouda, M.; El-Kholy, M.; Moustafa, S.; Hussien, A.; Wahba, M.; El-Shahat, M. Synthesis and Characterization of Nanosized F e 2 O 3 Pigments. International Journal of Inorganic Chemistry 2012, 2012, https://doi.org/10.1155/2012/989281.

7. Muhajir, M.; Puspitasari, P.; Razak, J.A. Synthesis and Applications of Hematite $\alpha$-Fe2O3: a Review. Journal of Mechanical Engineering Science and Technology (JMEST) 2020, 3, 51-58, https://doi.org/10.17977/um016v3i22019p051.

8. Hill, A.H.; Jacobsen, H.; Stewart, J.R.; Jiao, F.; Jensen, N.P.; Holm, S.L.; Mutka, H.; Seydel, T.; Harrison , A.; Lefmann, K. Magnetic properties of nanoscale hematite, $\alpha$-Fe2O3, studied by time-of-flight inelastic neutron spectroscopy. The Journal of chemical physics 2014, 140, 4891, http://dx.doi.org/10.1063/1.4862235.

9. Meijer, J.-M.; Rossi, L. Preparation, properties, and applications of magnetic hematite microparticles. Soft Matter 2021, https://doi.org/10.1039/D0SM01977A.

10. Lian, J.; Duan, X.; Ma, J.; Peng, P.; Kim, T.; Zheng, W. Hematite ( $\alpha$-Fe2O3) with various morphologies: ionic liquid-assisted synthesis, formation mechanism, and properties. ACS nano 2009, 3, 3749-3761, http://dx.doi.org/10.1021/nn900941e.

11. Chhabra, H.; Kumar, M. Size and shape dependent equation of state for nanomaterials with application to bulk materials. Journal of Physics and Chemistry of Solids 2020, 1, 109308 ,39 http://dx.doi.org/10.1016/j.jpcs.2019.109308.

12. Manukyan, K.V.; Chen, Y.-S.; Rouvimov, S.; Li, P.; Li, X.; Dong, S.; Liu, X.; Furdyna, J.K.; Orlov, A.; Bernstein, G.H. Ultrasmall $\alpha-\mathrm{Fe} 2 \mathrm{O} 3$ superparamagnetic nanoparticles with high magnetization prepared by template-assisted combustion process. The Journal of Physical Chemistry C 2014, 118, 16264-16271, http://dx.doi.org/10.1021/jp504733r.

13. Novoselova, L.Y. Hematite nanoparticle clusters with remarkably high magnetization synthesized from water-treatment waste by one-step "sharp high-temperature dehydration". RSC advances 2017, 7, 5129851302, https://doi.org/10.1039/C7RA09062E.

14. Daou, T.; Pourroy, G.; Bégin-Colin, S.; Greneche, J.-M.; Ulhaq-Bouillet, C.; Legaré, P.; Bernhardt, P.; Leuvrey, C;.Rogez, G. Hydrothermal synthesis of monodisperse magnetite nanoparticles. Chemistry of Materials 2006, 18, 4399-4404, http://dx.doi.org/10.1021/cm060805r.

15. Somwanshi, S.B.; Somvanshi, S.B.; Kharat, P.B. Nanocatalyst: A Brief Review on Synthesis to Applications. In Proceedings of the Journal of Physics: Conference Series 2020, 012046, http://dx.doi.org/10.3390/nano10050968.

16. Benhammada, A.; Trache, D.; Kesraoui, M.; Chelouche, S. Hydrothermal synthesis of hematite nanoparticles decorated on carbon mesospheres and their synergetic action on the thermal decomposition of nitrocellulose. Nanomaterials 2020, 10, 968, http://dx.doi.org/10.3390/nano10050968.

17. Badry, M.D.; Wahba, M.A.; Khaled, R.; Ali, M.M.; Farghali, A.A. Synthesis, characterization, and in vitro anticancer evaluation of iron oxide/chitosan nanocomposites. Inorganic and Nano-Metal Chemistry 2017, 47, 405-411, https://doi.org/10.1080/15533174.2016.1186064.

18. Badry, M.; Wahba, M.A.; Khaled, R.K.; Farghali, A. Preparation and Dielectric Properties of Magnetite/Chitosan Nanocomposite Film. Middle East Journal of Applied Sciences 2015.

19. Khalil, T.E.; Elhusseiny, A.F.; Ibrahim, N.M.; El-Dissouky, A. Unexpected effect of magnetic nanoparticles on the performance of aqueous removal of toxic $\mathrm{Cr}$ (VI) using modified biopolymer chitosan. International Journal of Biological Macromolecules 2021, 170, 768-779, https://doi.org/10.1016/j.ijbiomac.2020.12.188.

20. Nasrollahzadeh, M.; Shafiei, N.; Nezafat, Z. Synthesis of biopolymer-based metal nanoparticles. In Biopolymer-Based Metal Nanoparticle Chemistry for Sustainable Applications: Volume 1: Classification, Properties and Synthesis 2021, 2, 255.

21. Kumar, M.N.R. A review of chitin and chitosan applications. Reactive and functional polymers 2000, 46, 127, https://doi.org/10.1016/S1381-5148(00)00038-9.

22. Tajdini, K ;.Shakeri, A.; Naijian, F. Nanocomposite hydrogel of chitosan-g-poly acrylamide/ nanoclay: effect of degree of cross-linking on their swelling. Lett. in Appl. NanoBioSci 9, https://doi.org/10.33263/LIANBS92.995999.

23. Petrenko, I.; Khrunyk, Y ;.Voronkina, A.; Kovalchuk, V.; Fursov, A.; Tsurkan, D.; Ivanenko, V. Poriferan chitin: 3D scaffolds from nano-to macroscale. A review. Lett. Appl. Nanobiosci 2020, 9, 1004-1014, https://doi.org/10.33263/LIANBS92.10041014.

24. Mosmann, T. Rapid colorimetric assay for cellular growth and survival: application to proliferation and cytotoxicity assays. Journal of immunological methods 1983, 65, 55-63, http://dx.doi.org/10.1016/00221759(83)90303-4.

25. Duan, W.; Chen, C.; Jiang, L.; Li, G.H. Preparation and characterization of the graft copolymer of chitosan with poly [rosin-(2-acryloyloxy) ethyl ester]. Carbohydrate polymers 2008, 73, 582-586, http://dx.doi.org/10.1016/j.carbpol.2007.12.025.

26. Gregorio-Jauregui, K.M.; Pineda, M.; Rivera-Salinas, J.E.; Hurtado ,G.; Saade, H.; Martinez, J.L.; Ilyina, A.; López, R.G. One-step method for preparation of magnetic nanoparticles coated with chitosan. Journal of Nanomaterials 2012, 2012, http://dx.doi.org/10.1155/2012/813958. 
27. Lemine, O.; Alanazi, A.; Albert, E.L.; Hjiri, M.; M'hamed, M.O.; Alrub, S.A.; Alkaoud, A.; Abdullah, C.A.C. $\gamma$-Fe $2 \mathrm{O}$ 3/Gd $2 \mathrm{O}$ 3-chitosan magnetic nanocomposite for hyperthermia application: structural, magnetic, heating efficiency and cytotoxicity studies. Applied Physics A 2020, 126, 1-9 ,https://doi.org/10.1007/s00339020-03649-5.

28. Kaushik, A.; Solanki, P.R.; Ansari, A.A.; Sumana, G.; Ahmad, S.; Malhotra, B.D. Iron oxide-chitosan nanobiocomposite for urea sensor. Sensors and Actuators B: Chemical 2009, 138, 572-580, http://dx.doi.org/10.1016/j.snb.2009.02.005.

29. Chernyshova, I.; Hochella Jr, M.; Madden, A. Size-dependent structural transformations of hematite nanoparticles. 1. Phase transition. Physical Chemistry Chemical Physics 2007, 9, 1736-1750, http://dx.doi.org/10/1039.b618790k.

30. Cuong, N.D.; Hoa, T.T.; Khieu, D.Q.; Dai Lam, T.; Hoa, N.D.; Van Hieu, N. Synthesis, characterization, and comparative gas-sensing properties of $\mathrm{Fe} 2 \mathrm{O} 3$ prepared from $\mathrm{Fe} 3 \mathrm{O} 4$ and $\mathrm{Fe} 3 \mathrm{O} 4$-chitosan. Journal of alloys and compounds 2012, 523 ,http://dx.doi.org/10.1016/j.jallcom.2012.01.117.

31. Esmaeili, E.; Salavati-Niasari, M.; Mohandes, F.; Davar, F.; Seyghalkar, H. Modified single-phase hematite nanoparticles via a facile approach for large-scale synthesis. Chemical engineering journal 2011, 170, 278285, http://dx.doi.org/10.1016/j.cej.2011.03.010.

32. Ramya, S.S.; Mahadevan, C. Preparation and structural, optical, magnetic, and electrical characterization of $\mathrm{Mn} 2+/ \mathrm{Co} 2+/ \mathrm{Cu} 2+$ doped hematite nanocrystals. Journal of Solid State Chemistry 2014, 211, 37-50, https://doi.org/10.1016/j.jssc.2013.11.022 .

33. Tadic, M.; Panjan, M.; Damnjanovic, V.; Milosevic, I. Magnetic properties of hematite $(\alpha-\mathrm{Fe} 2 \mathrm{O} 3)$ nanoparticles prepared by hydrothermal synthesis method. Applied Surface Science 2014,187-183,320 , https://doi.org/10.1016/j.apsusc.2014.08.193.

34. Ge, J.; Hu, Y.; Biasini, M.; Beyermann, W.P.; Yin, Y. Superparamagnetic magnetite colloidal nanocrystal clusters. Angewandte Chemie International Edition 2007, 46, 4342-4345, http://dx.doi.org/10.1002/anie.200700197.

35. Stockhausen, H. Some new aspects for the modelling of isothermal remanent magnetization acquisition curves by cumulative log Gaussian functions. Geophysical research letters 1998, 25, 2217-2220, http://dx.doi.org/10.10298/9GL01580.

36. Karami, H.; Ordoukhanian, J.; Nezhadali, A. Pulse galvanostatic synthesis of superparamagnetic hematite nanorods in the presence of external magnetic field. Ceramics International 2015, 41, 14760-14765, http://dx.doi.org/10.1016/j.ceramint.2015.07.206

37. Seema, J.; Manoj, K.; Sandeep, C.; Geetika, S.; Mukesh, J.; Singh, V.N. Structural, magnetic, dielectric and optical properties of nickel ferrite nanoparticles synthesized by co-precipitation method. Journal of Molecular Structure 2014, 1076, 55-62 ,https://doi.org/10.1016/j.molstruc.2014.07.048.

38. Sunilkumar, M.; Gafoor, A.A.; Anas, A.; Haseena, A.P.; Sujith, A. Dielectric properties: a gateway to antibacterial assay - a case study of low-density polyethylene/chitosan composite films. Polymer journal 2014, 46, 422-429, http//:dx.doi.org/10.1038/pj.2014.19.

39. Mourya, V.; Inamdar, N.N.; Tiwari, A. Carboxymethyl chitosan and its applications. Advanced Materials Letters 2010, 1, 11-33, http://dx.doi.org/10.5185/amlett.2010.3108.

40. Varma, A.; Deshpande, S.; Kennedy, J. Metal complexation by chitosan and its derivatives: a review. Carbohydrate Polymers 2004, 55, 77-93, https://doi.org/10.1016/j.carbpol.2003.08.005 .

41. Guibal, E. Interactions of metal ions with chitosan-based sorbents: a review. Separation and purification technology 2004, 38, 43-74, http://dx.doi.org/10.1016/j.seppur.2003.10.004.

42. Monteiro Jr, O.A.; Airoldi, C. Some thermodynamic data on copper-chitin and copper-chitosan biopolymer interactions. Journal of Colloid and Interface Science 1999, 212, 212-219, http://dx.doi.org/10.1006/jcis.1998.6063. 